\title{
Simulation Study of Milling Force and Milling Temperature for High Speed Milling Thin-Wall SKD11 Hardened Steel Part
}

\author{
Tang De Wen ${ }^{a}$, Zhao ruilan ${ }^{b}$, Lv Xi Jian ${ }^{\mathrm{c}}$, Liu Jun $^{\mathrm{d}}$ \\ School of Mechanical Engineering, University of South China, Hengyang, Hunan, China, 421001.

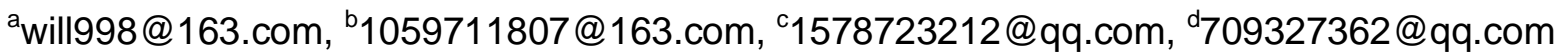

Keywords: Milling force, milling temperature, finite element model

Abstract: Both milling force and temperature are the key influence factor of thin-wall part deformation. Therefore, to study the influence of milling parameters including milling speed, feed per tooth, radial depth of cutting and axial depth of cutting on milling force and temperature in the cutting process, the finite element model of high speed milling thin-wall SDK11 hardened steel part is developed by DEFORM-3D based on the modified J-C material model. The results indicate that milling force increases with an increase of milling speed until milling speed beyond $400 \mathrm{~m} / \mathrm{min}$ began to decline, and milling temperature increases with an increase of cutting speed. Milling force rises with fluctuations with an increase of milling speed, and milling temperature increases with an increase of milling feed, But it appears a decline trend from milling feed of $0.02 \mathrm{~mm} / \mathrm{z}$ to $0.025 \mathrm{~mm} / \mathrm{z}$. Both milling force and temperature are increasing with the radial and axial depth of cut increasing. but milling force decline and milling temperature increase rapidly from axial depth of $0.7 \mathrm{~mm}$ to $0.8 \mathrm{~mm}$.

\section{Introduction}

SKD11 steels are some of the high hardness and strength, wear-resistant materials which are extensively utilized in the aerospace and the mold industry for thin-wall parts, gas turbine engines, casing, etc. The machined components used in these application fields require high dimensional accuracy and good surface quality. However, from machining view point, SKD11 steels are representative 'difficult-to-machine' materials. High-speed milling is one of the key technologies in 'difficult-to-machine' materials manufacturing at present, which can effectively shorten machining time, improves the machining efficiency and the quality ${ }^{[1]}$. In the milling process, thin wall part deformation and machining surface quality are directly influenced by milling force and milling temperature. The analysis of milling force and milling temperature due to machining operation has been an active subject of research. Milling force and milling temperature is mainly affected by milling parameters including milling speed, feed per tooth, radial depth and axial depth of cut in the cutting process. Therefore, using the SKD11 milling process model to understand the change laws of milling force and milling temperature with machining parameters is vital for improving machined surface quality and reducing deformation in various application filed.

In the past, numerous researchers have worked on experimental and analytical modeling of milling force and milling temperature evolution in machining processes. The two-dimensional transient finite element model of machining force and temperature was developed by Wang ${ }^{[2]}$ based on the thermal mechanical coupling. The result shows that the axial depth of cut and feed per tooth are the most significant factors on machining force and temperature in machining 7050 aluminium alloys processes. ZHANG et al. developed the flow stress constitutive model to simulate machining process of 7055 aluminium alloys ${ }^{[3]}$, using Deform-3D. The result shows that milling force and 
cutting edge temperature increase with an increase of milling speed, feed per tooth and axial depth of cut. LIU Dong et al. ${ }^{[5]}$ investigated the effects of cutting speed and feed on cutting force and temperature in turning silicoaluminum with PCD tools. LONG et al. ${ }^{[6]}$ developed a relationship between the residual stresses and coupling thermal-force, and the influences of machining force and temperature on the surface quality are studied. Typical orthogonal cutting model is established based on DEFORM-2D by He Zhen et $\mathrm{al}^{[7]}$. The model formulation incorporates cutting thickness, contact length between cutting tool and the workpiece.

Main contribution of the present work can be summarized as follows, the finite element model of high speed milling thin-wall SDK11 hardened steel part is developed by using DEFORM-3D based on the modified J-C material model, and the effect of milling parameters including milling speed, feed per tooth, radial depth of cut and axial depth of cut on milling force and temperature in milling process are studied.

\section{Numerical model description}

A thermo-mechanically coupled finite element model of high speed milling process was developed to predict milling force and milling temperature for thin-wall SKD11 steels part by using DEFORM-3D. Several development stages are necessary to build a model which can generate more accurate predictions. Firstly, appropriate mesh density and remesh criteria can effectively shorten simulation time and avoid mesh distortion due to large deformation at the cutting zone. Secondly, material constitutive equation is important to accurately predict cutting force and cutting temperature as it is a function of strain, strain rate and temperature to characterize the flow stress behavior of SKD11 steels in machining process. Lastly, boundary conditions including the thermal conductivity, the friction model, machining parameters should be assumed in order to reach the real processing situation as far as possible.

The geometry of the end mill and the thin-wall part were built in Pro/ENGINEER in advance. The geometry parameters of the end mill as follows: diameter of $2 \mathrm{~mm}$, rake angle of $8^{\circ}$, relief angle of $10^{\circ}$, helical angle of $45^{\circ}$. The workpiece was meshed with $10^{5}$ linear tetrahedral elements and defined as an elasto-plastic body. Meanwhile, the rigid tool was meshed with 20000 linear tetrahedral elements. The updated Lagrange remeshing and solution scheme were used to overcome severely distorted elements during large plastic deformation, and the local remeshing was conducted on the workpiece with a minimum mesh size of $10^{-5} \mathrm{~m}$. In order to realize the milling process, the workpiece could move along the Y direction, but the bottom of the workpiece was fixed in $\mathrm{X}$ and $\mathrm{Z}$ direction, and the cutting tool just rotated on the spot. The relative position relation between the workpiece and the cutting tool was shown in Fig 1.

The modified J-C constitutive equation and its constants are shown respectively in Eq. 1 and Tab.3. The effect of material recrystallization on the flow stress was taken into consideration in the typical J-C constitutive. In this work, the modified J-C constitutive equation was used to describe the deformation process of metal materials under high temperature, large strain and high strain rate, which equation was given in Eq1.

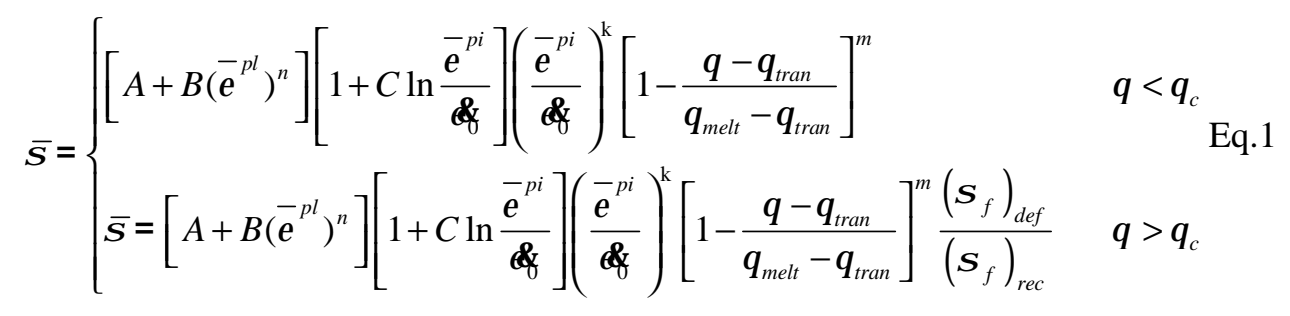


$\left(\sigma_{f}\right)_{d e f},\left(\sigma_{f}\right)_{\text {rec }}$ are flow stress before and after material crystallization, $\theta_{\mathrm{c}}$ is recrystallization temperature, other parameters can obtain through the experiment of split Hopkinson pressure bar (SHPB). J-C equation constants used in this work are presented in Tab 1.

Tab 1. J-C equation constants of SKD11 hardened steel

\begin{tabular}{ccccccccccc}
\hline $\mathrm{A}$ & $\mathrm{B}$ & $\mathrm{n}$ & $\mathrm{C}$ & $\mathrm{m}$ & $\mathrm{k}$ & $\theta_{\text {tran }}$ & $\theta_{\text {melt }}$ & $\left(\sigma_{f}\right)_{\text {def }}$ & $\left(\sigma_{f}\right)_{\text {rec }}$ & \& 8 \\
\hline 2480 & 1440 & 0.45 & 0.012 & 1.1 & 0.01 & 20 & 1500 & 800.094 & 1560.975 & 0.01 \\
\hline
\end{tabular}

Boundary conditions were assumed by means of the DEFORM pre-processor. Cut length of $1 \mathrm{~mm}$ was modeled. A room temperature of $20^{\mathrm{c}} \mathrm{C}$ was assigned to the workpiece as well as the tool, the environment of machining. To the workpiece, the thermal conductivity considered in the analysis was varied linearly as a function of temperature between $20^{\circ} \mathrm{C}(42.58)$ and $1020^{\circ} \mathrm{C}(17.04)$, the heat capacity was also varied linearly as a function of temperature between $20^{\circ} \mathrm{C}(3.6)$ and $1020^{\circ} \mathrm{C}(7.64)$. Heat transfer coefficient was set as $11 \mathrm{~W} /\left(\mathrm{m}^{2}{ }^{\circ} \mathrm{C}\right)$ and the coulomb friction law along with a coefficient of friction of 0.6 was used inside the workpiece. The shear friction law along with a coefficient of friction of 0.4 was used between cutting tool and the workpiece. Mechanical properties for SKD11 as per the material certificate are presented in Tab 2.

Tab 2. Material properties for SKD11 hardened steel

\begin{tabular}{ll}
\hline \multicolumn{2}{c}{ SKD11 harden steel mechanical properties } \\
\hline Yong's modulus $(\mathrm{GPa})$ & 210000 \\
Poisson's ratio & 0.28 \\
Thermal expansion $\left(\mathrm{mm} / \mathrm{m}^{\circ} \mathrm{C}\right)$ & 20 \\
Density & $7.7 \times 10^{3} \mathrm{~kg} / \mathrm{m}^{3}$ \\
Hardness(HBS) & 255 \\
\hline
\end{tabular}

Tab 3. Milling parameters and its condition

\begin{tabular}{cc}
\hline Milling parameters & Condition \\
\hline Cutting speed $(\mathrm{m} / \mathrm{min})$ & $200,300,350,400,450,500$ \\
Feed per tooth $(\mathrm{mm} / \mathrm{Z})$ & $0.01,0.015,0.02,0.025,0.03,0.035$ \\
Radial depth of cut & $0.1,0.12,0.14,0.16,0.18,0.2$ \\
$(\mathrm{~mm})$ & \\
Axial depth of cut $(\mathrm{mm})$ & $0.2,0.4,0.5,0.6,0.7,0.8$ \\
\hline
\end{tabular}

To analyse the effect of milling parameters on milling force and milling temperature in the milling process, single factor simulations would be carried on. There were four milling parameters include cutting speed, feed per tooth, radial depth of cut and axial depth of cut, simulation should be performed six times to every parameters in order to obtain accurate data, milling parameters and its condition were given in Tab 3.

\section{Result and analyses}

In this section, the influences of milling parameters on milling force and milling temperature are discussed. Milling parameters include the milling speed, feed per tooth, radial depth of cut and axial depth of cut.

\section{Effect of milling speed on milling force and milling temperature}

The influence of milling speed variation on milling force and milling temperature was analysed for six different speed: $V=200 \mathrm{~m} / \mathrm{min}, 300 \mathrm{~m} / \mathrm{min}, 350 \mathrm{~m} / \mathrm{min}, 400 \mathrm{~m} / \mathrm{min}, 450 \mathrm{~m} / \mathrm{min}, 500 \mathrm{~m} / \mathrm{min}$, other milling parameters as follow: feed per tooth $\mathrm{fz}=0.01 \mathrm{~mm} / \mathrm{z}$, radial depth of cut $\mathrm{Ae}=0.1 \mathrm{~mm}$, axial depth of cut $\mathrm{Ad}=0.8 \mathrm{~mm}$.

The effect of milling speed variation on milling force and milling temperature is shown in Fig3. It is observed that milling component force in all direction show similar change law from Fig 2, at the speed of $200-300 \mathrm{~m} / \mathrm{min}$, milling force increase and milling temperature declines slightly with an increase cutting speed. However, at a speed of the $300-350 \mathrm{~m} / \mathrm{min}$, milling force decline slightly, but milling temperature increases rapidly. At the speed of $350-400 \mathrm{~m} / \mathrm{min}$, milling force increase slightly and milling temperature declines rapidly. Above $400 \mathrm{~m} / \mathrm{min}$, milling force decline rapidly and 
milling temperature increases rapidly with an increase milling speed. it is observed that milling force have an opposite change law with milling temperature. The influence of milling speed can be explained by the strain rate strengthening effect due to the strain rate and the thermal softening effect due to heat which both are strengthened with an increase speed, The higher the speed, the greater both the strain rate and the plastic deformation heat. But the impact of the strain rate strengthening effect is different from the thermal softening effect.

Specifically, the strain rate strengthening effect occupies a leading position in the region of the workpiece below the cutting edge in low speeds $(200-300 \mathrm{~m} / \mathrm{min})$, which result in milling force increase and milling temperature declines with an increase speed. In medium speeds $(300-400 \mathrm{~m} / \mathrm{min})$, the strain rate strengthening effect is equal with the thermal softening effect, so the fluctuant of both milling force and milling temperature are few. In high speeds $(>400 \mathrm{~m} / \mathrm{min})$, milling force decline rapidly due to the thermal softening effect playing a role.

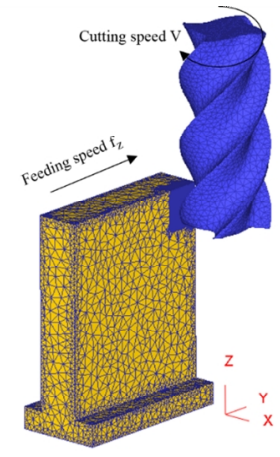

Fig 1. 3-D finite element model of machining thin-wall SKD11 steels part

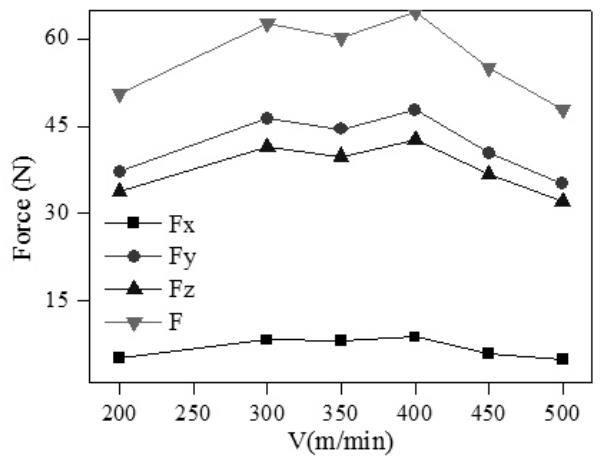

(a) Force

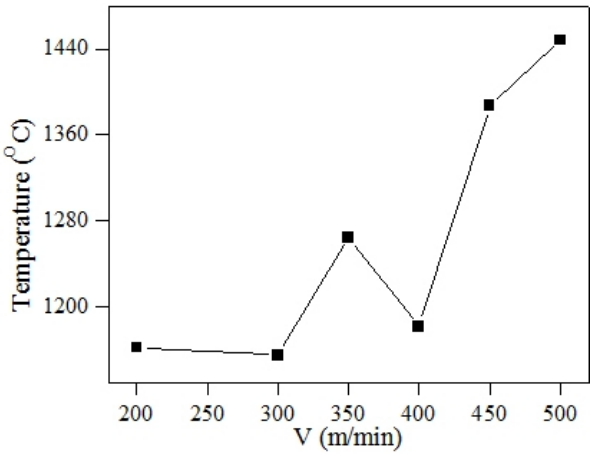

(b) Temperature

Fig 2. Effect of milling speed on milling force and milling temperature

\section{Effect of feed on milling force and milling temperature}

The influence of feeds on milling force and milling temperature was studied for six different feeds per tooth: $0.001 \mathrm{~mm}, 0.015 \mathrm{~mm}, 0.02 \mathrm{~mm}, 0.025 \mathrm{~mm}, 0.03 \mathrm{~mm}, 0.35 \mathrm{~mm}$, Other parameters as follow: cutting speed $V=200 \mathrm{~m} / \mathrm{min}$, radial depth of cutting $A e=0.1 \mathrm{~mm}$, axial depth of cutting $\mathrm{Ad}=0.8 \mathrm{~mm}$.

From Fig 3, it is observed that the trend of milling force is opposite with milling temperature's. At the feed of 0.01-0.02, milling force declined and milljng temperature increases with an increase feed. As the feeds increase from $0.02 \mathrm{~mm}$ to $0.025 \mathrm{~mm}$, milling force increase rapidly and milling temperature declines. Above $\mathrm{fz}=0.25 \mathrm{~mm}$, milling force declined slightly but milling temperature increases all through. It is remarkable that milling temperature isn't increasing continuously with the increase of the feed, but rising first, then declining before it rises again. This phenomenon can be explained by SF.H et al. In their study, temperature field was studied based on moving heat source theory in high speed milling process. Results showed that the relationship between the highest milling temperature and feed isn't a simple positive correlation but a second round effect in machining process. Exactly, the highest machining temperature always increases with an increase feed, but declines in a range. 


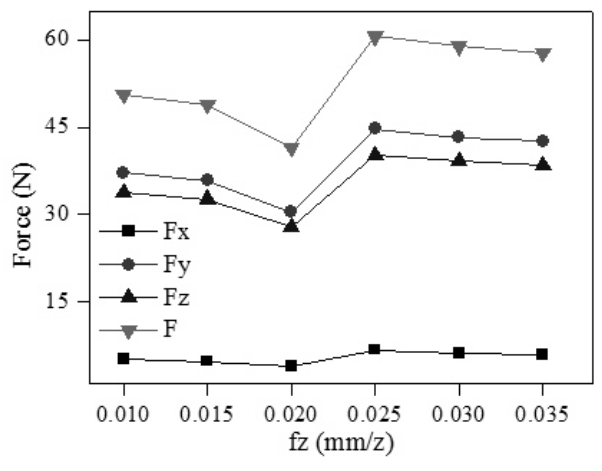

(a) Force

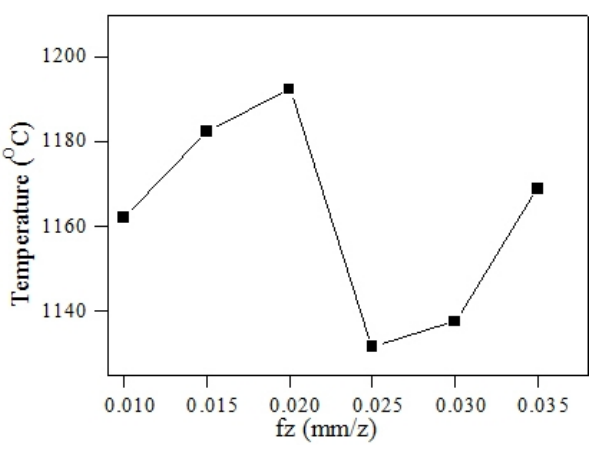

(b) Temperature

Fig 3. Effect of feed on milling force and temperature

\section{Effect of radial depth of cut on milling force and milling temperature}

The influence of radial depth of cutting on milling force and milling temperature was studied for six different radial depth of cutting: Ae $=0.1 \mathrm{~mm}, 0.12 \mathrm{~mm}, 0.14 \mathrm{~mm}, 0.16 \mathrm{~mm}, 0.18 \mathrm{~mm}, 0.2 \mathrm{~mm}$. Other parameters as follows: cutting speed $\mathrm{V}=200 \mathrm{~m} / \mathrm{min}$, axial depth of cutting $\mathrm{Ad}=0.8 \mathrm{~mm}$, feed per tooth $\mathrm{fz}=0.01 \mathrm{~mm} / \mathrm{z}$.

From Fig4, it is obvious that both milling force and milling temperature increase with an increase radial depth of cutting. The phenomenon can be explained as follow: in case of other factors being equal, the volume of chip increases due to an increase radial depth of cutting, which directly leads to the contact area between the cutting tool and chip as well as deformation of chip increases. Further, milling force increase due to the increase of deformation resistance of chip as well as friction between cutting tool and chip. Meanwhile, the generation of heat by local friction and deformation result in milling temperature increasing.

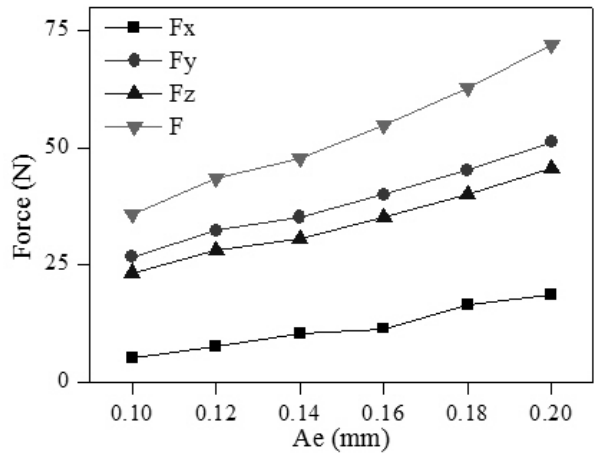

(a) Force

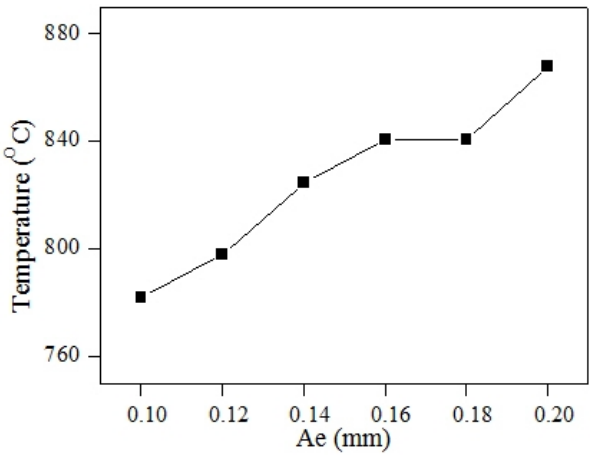

(b) Temperature

Fig 4. Effect of radial depth of cut on milling force and temperature

\section{Effect of axial depth of cut on milling force and milling temperature}

The influence of axial depth of cut on milling force and milling temperature was studied for six different axial depths of cutting: $\mathrm{Ad}=0.2 \mathrm{~mm}, 0.4 \mathrm{~mm}, 0.5 \mathrm{~mm}, 0.6 \mathrm{~mm}, 0.7 \mathrm{~mm}, 0.8 \mathrm{~mm}$. Other parameters as follows: cutting speed $\mathrm{V}=200 \mathrm{~m} / \mathrm{min}$, radial depth of cutting $\mathrm{Ae}=0.1 \mathrm{~mm}$, feed per tooth $\mathrm{fz}=0.01 \mathrm{~mm} / \mathrm{z}$.

From Fig 5, milling force and milling temperature are rising with axial depth of cut increasing from $0.3 \mathrm{~mm}$ to $0.7 \mathrm{~mm}$. The trend can be explained by the width of cutting layer increasing. The width of cutting layer increases due to axial depth of cut increasing in machining process, then the contact area increases between the cutting tool and the workpiece, and this directly result in cutting resistance increasing, finally milling force increase with it. But the heat generated from local deformation and frication force don't increase. This results in milling temperature waves in a small range. When axial depth of cut goes over $0.7 \mathrm{~mm}$, milling force decline slightly but milling 
temperature rises rapidly. The reason is that the thermal softening effect plays an important role in this stage.

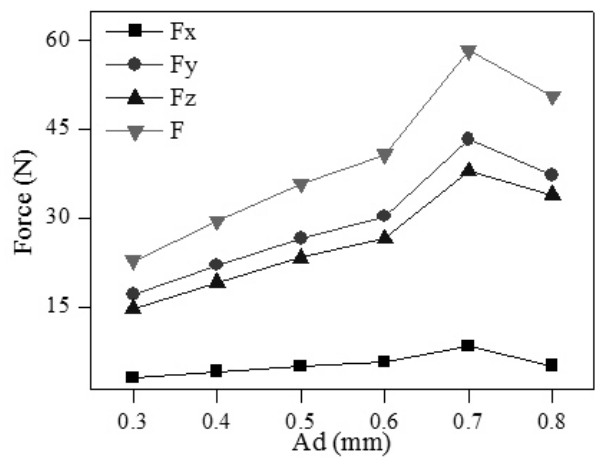

(a) Force

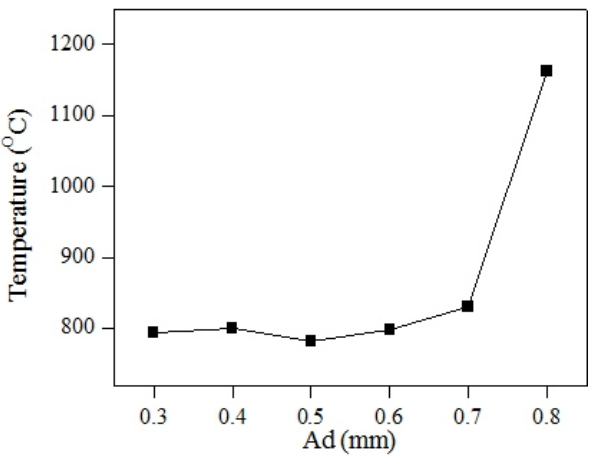

(b) Temperature

Fig 5. Effect of axial depth of cut on milling force and temperature

\section{Conclusions}

Based on this work, the following conclusions can be draw:

$u$ The change law of milling force is opposite with milling temperature with the milling speed increasing. Both milling force and milling temperature wave slightly at a cutting speed of $300-400 \mathrm{~m} / \mathrm{min}$, but milling force increases and milling temperature declines slightly when cutting speed increases from $200 \mathrm{~m} / \mathrm{min}$ to $300 \mathrm{~m} / \mathrm{min}$, and when cutting speed change from $400 \mathrm{~m} / \mathrm{min}$ to $500 \mathrm{~m} / \mathrm{min}$, resultant tool force declines from $64 \mathrm{~N}$ to $48 \mathrm{~N}$ and milling temperature increases from $1182^{\circ} \mathrm{C}$ to $1448^{\circ} \mathrm{C}$.

$\mathrm{u}$ The effect of feed per tooth on milling force and milling temperature shows the quadratic effect. Specifically, milling force rises slightly and temperature declines rapidly from $1192^{\circ} \mathrm{C}$ to $1131^{\circ} \mathrm{C}$ with feed per tooth from 0.02 to $0.025 \mathrm{~mm} / \mathrm{z}$, and milling force shows a downtrend, milling temperature shows an uptrend with an increase feed per tooth in a range of other.

$\mathrm{u}$ Milling force and milling temperature mainly keep rising trend with the axial and radial depth of cut increasing. Remarkably, milling temperature rise rapidly from $830^{\circ} \mathrm{C}$ to $1162{ }^{\circ} \mathrm{C}$ and milling force declines suddenly from $58 \mathrm{~N}$ to $50 \mathrm{~N}$ due to the thermal softening effect when the axial depth of cut increase from $0.7 \mathrm{~mm}$ to $0.8 \mathrm{~mm}$.

\section{Acknowledgements}

The research work was supported by China Postdoctoral Science Foundation funded under Grant No. 2013M542123, Natural science foundation of Hunan Province under Grant No. 2015JJ5023. Outstanding young project in hunan province department of education under Grant No. 5B206 and Supported by the construct program of the key discipline in hunan province, and Cooperative innovation center for nuclear fuel cycle technology \& equipment.

\section{References}

[1] R.S. Pawadea, Suhas S. Joshia, P.K. Brahmankar. Effect of machining parameters and cutting edge geometry on surfaceintegrity of high-speed turned Inconel 718[J]. International Journal of Machine Tools \& Manufacture. Vol. 48 (2008), pp.15

[2] Wang Bo. Simulation Study on Milling Force and Temperature in High-speed Milling of 7050-T7451 Aluminum Alloy [J]. MACHINE TOOL \& HYDRAULICS, vol. 16 (2014), pp. 
[3] ZHANG Zhao-yang , CHEN Guo-ding, WANG Tao. Study on the Milling Force and Milling Temperature for End Milling of Aluminum Alloy 7055[J]. Machinery Design \& Manufacture, vol. 4 (2014), pp. 75

[4] Xu Sheng-fu ,Chen Hui-xian ,Chen Ming ,et al. Study on milling force and milling temperature distribution of milling cutter with fir-slot [J]. Modern Manufacturing Engineering. Vol. 1 (2015), pp. 78

[5] LIU Dong, CHEN Wu-yi, et al. Cutting Force and Cutting Temperature of Turning Al-Si Alloy[J]. Nonferrous Metals, vol. 1 (2006), pp.39

[6] LONG Zhen-hai, ZHAO Wen-xiang, WANG Xi-bin. Experimental Research on Surface Reinforcement Mechanism Introduced by Coupling Effect of Cutting Forces and Heat[J]. OURNAL OF AERONAUTICAL MATERIALS, vol. 6 (2007), pp.45

[7] He Zhen-wei, Quan Yan-ming, Yue You-shu. Study on Cutting Heat in High-Speed Cutting Based on FEM Simulation[J]. Tool Engineering, vol. 3 (2006), pp.60 